\title{
Global energy demand projection based on the GESDA model
}

\author{
Ding MA, Fagen ZHU \\ Department of Economy and Energy Supply \& Demand Research \\ State Grid Energy Research Institute \\ Beijing, China \\ martin8725@126.com; zhufagen@sgeri.sgcc.com.cn
}

Keywords:global; energy demand; energy system model; carbon emission

\begin{abstract}
A global energy demand projection model (GESDA), including the global energy service demand module, the energy system optimization module and the carbon emission module, for projections of global energy service demand, energy demand and supply, and associated carbon emissions. Projections of global energy demand and carbon emissions for main energy-intensive sectors are made based on assumptions concerning future population and economic growth. The results show: 1 ) In the $2^{\circ} \mathrm{C}$ Scenario, from 2014 to 2050, global primary energy demand will increase from 20.1 billion tce to nearly 30.0 billion tce; 2) From 2014 to 2050, the supply of non-fossil energy will increase by 3.8 times and its proportion to the supply of primary energy will ascend over $50 \%$; 3 ) carbon emission will increase from 33.5 billion tons in 2014 to 36.0 billion tons in 2025, followed by negative increase. By 2050, the emission will drop to 11.5 billion tons, about 50\% of that in 1990 .
\end{abstract}

\section{Introduction}

A changing world is asking challenging questions of the established energy powers. Will fossil fuels surrender their supremacy in the electricity sector? And can the nations of the world strike an effective, collective climate bargain? Lower oil prices have squeezed capital investment, boosted demand, put pressure on exporters and emboldened some countries to reform fossil-fuel subsidies. But key questions remain around the lifespan of OPEC's current strategy and how long higher cost producers can endure lower oil prices. The rapid expansion of traded coal supply in recent years, coupled with the first decline in global demand this century, has prompted a sharp drop in coal prices. Global investments in renewables have been strong while costs have continued to fall, but government support remains essential in most markets. Energy efficiency policies are having a notable impact on demand, but lower prices also bring the risk that consumption grows more strongly and policy efforts falter. Energy has been at the heart of many international policy discussions, with the G7 focusing on energy sector decarbonisation and energy security, the G20 delivering action plans on energy efficiency and energy access, the United Nations including energy explicitly within its post-2015 Sustainable Development Goals and intense efforts by policy-makers to prepare the ground for the critical climate meeting in Paris in December 2015 (COP21). Rarely has energy featured so prominently in so many fora, but will the world's energy system undergo a gradual transition or a rapid and fundamental transformation in the decades to come?

\section{Model principle}

This paper uses the Global Energy Supply-Demand Analysis (GESDA) Model developed by State Grid Energy Research Institute (SGERI) to make quantitative study. Combining bottom-up and top-down strategies, the model observes the logic of final energy demand-primary energy supply—environment 
friendly energy emission1. Techniques used in the model include time sequence, trend extrapolation, econometrics, unit product energy consumption analysis, unit output consumption analysis, turnover energy consumption, and energy system analysis. The model makes analog calculation of final energy demand, and on this basis calculates by fuel the total primary energy demand, supply and $\mathrm{CO}_{2}$ emission through energy system analysis, with consideration given to such transformation processes as power generation, heat supply, oil refining and coking, and taking $\mathrm{CO}_{2}$ reduction as the primary target and energy supply-demand equilibrium, energy resources, environmental capacity, productivity, transformation capacity, clean energy development objectives and investment cost as constraints (figure $1)$.

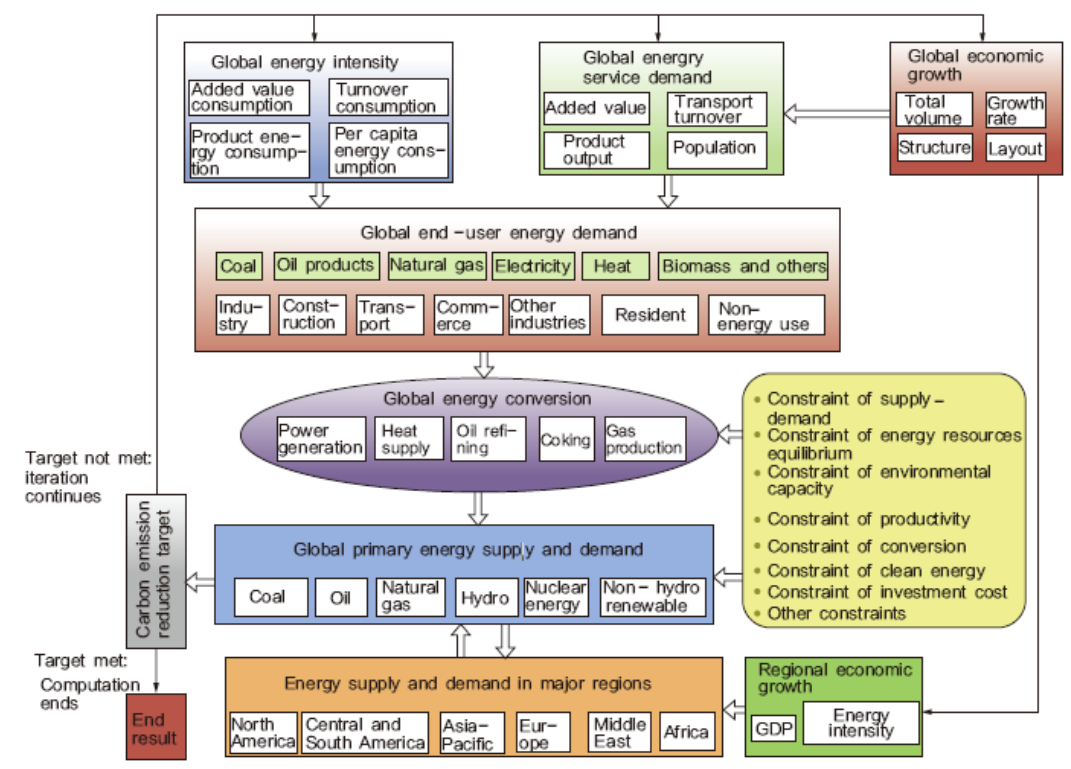

Figure 1. Framework of Global Energy Supply-Demand Analysis Model

\section{Scenario design}

At the 21st UN Conference on Climate Change held at the end of 2015, 195 countries and regions unanimously approved the Paris Agreement which sets a goal of limiting global warming to less than $2{ }^{\circ} \mathrm{C}$ and will pursue efforts to limit the temperature increase to $1.5^{\circ} \mathrm{C}$. This study, based on the strategy for Global Energy Interconnection and considering comprehensive factors including economy, community, technology, environment and resources, designs the global energy supply-demand scenario focusing on the $2^{\circ} \mathrm{C}$ target (the $2^{\circ} \mathrm{C}$ Scenario, with the projection period up to the year 2050). The parameters and hypotheses are listed in Table 1. 
Table1.Main parameters and hypotheses

\begin{tabular}{|c|c|c|c|c|c|}
\hline \multirow{4}{*}{$\begin{array}{c}\text { Economic and } \\
\text { social indicators }\end{array}$} & 2020 & 2030 & 2040 & 2050 \\
\cline { 2 - 5 } & Primary industry (\%) & 2.9 & 2.5 & 2.3 & 2.1 \\
\cline { 2 - 6 } & Secondary industry (\%) & 25.2 & 24.1 & 22.0 & 18.5 \\
\cline { 2 - 6 } & Tertiary industry (\%) & 72.0 & 73.3 & 75.6 & 79.3 \\
\cline { 2 - 6 } Industry & Population (billion) & 7.7 & 8.5 & 9.1 & 9.7 \\
\hline \multirow{4}{*}{ Transport } & Crude steel (billion ton) & 1.77 & 1.82 & 1.74 & 1.57 \\
\cline { 2 - 6 } & Cement (billion ton) & 4.4 & 4.55 & 4.4 & 3.95 \\
\cline { 2 - 6 } & $\begin{array}{c}\text { Primary aluminum (million } \\
\text { ton) }\end{array}$ & 57.5 & 59.5 & 58.5 & 19 \\
\cline { 2 - 6 } & Copper ore (million ton) & 21 & 22.5 & 22 & 0.8 \\
\cline { 2 - 6 } & $\begin{array}{c}\text { Aviation converted } \\
\text { turnover }\end{array}$ & 0.6 & 0.7 & 0.7 & 28.3 \\
\cline { 2 - 6 } & $\begin{array}{c}\text { Highway converted } \\
\text { turnover }\end{array}$ & 20.8 & 24.6 & 26.9 & 20.5 \\
\cline { 2 - 6 } & $\begin{array}{c}\text { Railway converted } \\
\text { turnover }\end{array}$ & 14.6 & 16.8 & 18.7 & \multirow{2}{*}{0.5} \\
\hline
\end{tabular}

\section{Modeling results}

\section{Primary energy demand.}

Global demand for primary energy will keep increasing and the growth will slow down. In the $2^{\circ} \mathrm{C}$ Scenario (the same below), world's primary energy demand will increase from 20.1 billion to 30.0 billion tce, indicating an average annual growth of $1 \%$. As the economy slows down and energy intensity relaxes, the growth will gradually ease down, and stabilize at around 30.0 billion tce after 2045 .

Structure of primary energy demand will keep improving around the world, transforming from a fossil energy-based and clean energy supplemented to a clean energy-based and fossil energy supplemented pattern. Coal consumption declines in industry \& commerce and resident sectors and climbs reluctantly in power generation and heat supply sectors, coal demand will approach to the climax by 2025 (Figure 2). Oil demand is influenced by the rapid development of electrical vehicles and will not be the top energy source. By 2050, its proportion to primary energy demand will get down to $10 \%$. Natural gas demand will keep increasing before 2040, and after that will decline in power generation, industry and transport sectors, and the total demand will start negative growth. Non-fossil energy will continue rapid development, and will take the place of fossil energy as the dominant energy after 2040. Its proportion to primary energy demand will reach $72.7 \%$ by 2050 , or about $80 \%$ if non-energy use is excluded from the total demand.

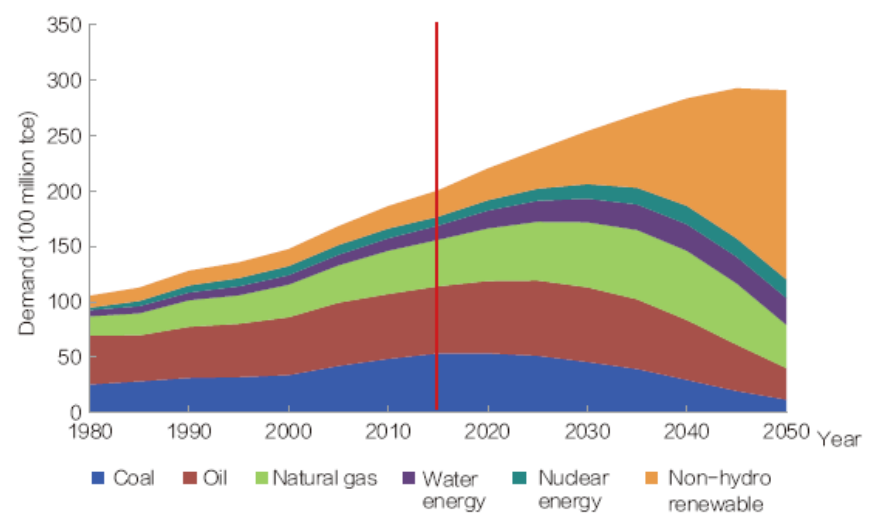

Figure 2. Primary energy demand by fuel, $1980-2050$ 


\section{Final energy demand.}

Final energy demand will hit the climax around 2035. The suspension of demand growth is mainly caused by the slowing down economy and decrease of energy intensity. From 2014 to 2050, final energy demand will increase from 13.3 billion tce to 15.2 billion tce. Before 2035, the total final energy demand will keep increasing up to 16.7 billion tce, but the driving power for the increase is getting weaker. After 2035, the economy will keep slowing down, energy demand of iron \& steel and building material sectors will shrink, and other sectors will boast remarkable improvement of electricity application and efficiency, dragging the total energy demand to negative growth. The final energy demand will decline by around $10 \%$ from the climax by 2050.

Resident, commerce and industry will present the most final energy demand growth. From 2014 to 2050, the demand of resident, commerce and other sectors will increase from 4.6 billion tce to 6.3 billion tce, and the proportion of energy consumption in such sectors to the total final energy demand will exceed $40 \%$ by 2050; energy demand of industry will increase from 3.8 billion to 4.5 billion tce, an annual average growth of $0.5 \%$, and reach the climax in around 2040; that of transport will keep ascending and hit the climax in around 2030 (about 4.3 billion tce), and then slide down to 2.9 billion tce by 2050 due to the wide application of electric vehicles, electricity application in railway and the rapid development of rail transport that significantly improve comprehensive efficiency (Figure 3).

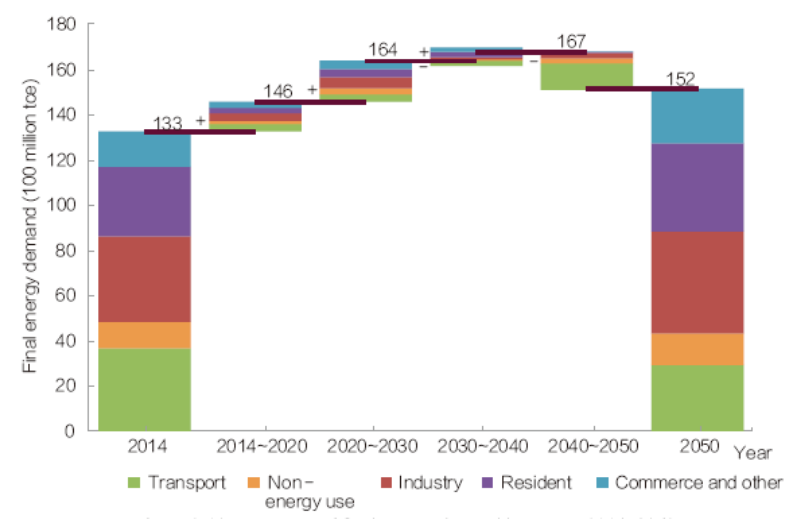

Figure 3. Primary energy demand by fuel, 1980-2050

\section{Energy supply.}

Clean alternative is the development trend of final energy supply structure. From 2014 to 2050, the supply of non-fossil energy will present an annual average growth of $4.4 \%$, and its proportion to primary energy supply will be lifted to around $73 \%$ or nearly $80 \%$ if non-energy use is excluded. Specifically, the supply of wind and solar energy will increase by 30 and 80 times respectively, and together account for over $50 \%$ of primary energy supply by 2050; the supply of fossil energy such as coal, oil and natural gas will drop nearly $50 \%$ from 15.6 billion to 7.9 billion tce, and the proportion will fall by 50 percentage points. See Figure 4 for world energy flow chart. 


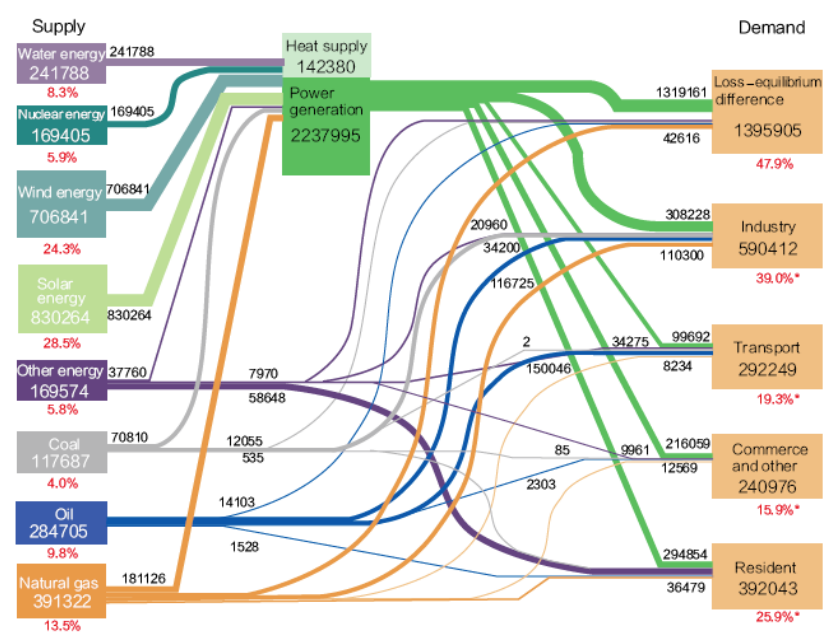

Figure 4. Framework of Global Energy Supply-Demand Analysis Model

\section{Carbon emissions.}

$\mathrm{CO}_{2}$ emission will increase from 33.5 billion in 2014 to 36 billion in 2025, followed by negative growth; after 2030, $\mathrm{CO}_{2}$ emission will remarkably decrease, down to 11.5 billion tons by 2050, about $50 \%$ of that in 1990; the total emission will be less than 1.1 trillion tons, falling in the target range in the $2{ }^{\circ} \mathrm{C}$ Scenario. The carbon emission growth rate which about $3 \%$ annually in average, will display a large scissors difference with the consumption growth of primary energy mainly due to the rapid improvement of clean energy application and expanding application of CCS.

From 2014 to 2050, as coal consumption remarkably shrinks and CCS is applied to coal-fired power plant, iron \& steel and building material sectors, $\mathrm{CO}_{2}$ emission from coal consumption will decrease from 14.7 billion to 1.9 billion tons. Coal will be the third largest emission source next to but its aggregated emission is higher than oil and natural gas. As for oil, due to shrinking end-user demand and CCS application to oil refining, the $\mathrm{CO}_{2}$ emission will drop down to 4.41 billion tons by 2050, 2/3 less than that in 2014. $\mathrm{CO}_{2}$ emission from gas consumption will be 5.1 billion tons by 2050, reducing by about $1 / 4$ over 2014 and accounting for over $40 \%$ of total emission.

From the modelling results, about $90 \%$ of world's power generation will generate from non-fossil energy by 2050, and $\mathrm{CO}_{2}$ emission from power generation (excluding heat supply) will reduce by around 9.5 billion tons, contributing $42.6 \%$ of global carbon emission reduction; through promoting electricity replacement in the supply side, the proportion of electricity consumption in industry (excluding nonenergy use), transport, resident, commerce and other sectors to the final energy demand will each increase by over 30 percentage points, and their $\mathrm{CO}_{2}$ emission will sharply decrease and contribute $47.6 \%$ to global carbon emission reduction.

\section{Results}

In this study, the global energy demand and supply and its associated carbon emissions are projected. The main results are as follows:

(1) In the $2^{\circ} \mathrm{C}$ Scenario, from 2014 to 2050, global primary energy demand will increase from 20.1 billion tce to nearly 30.0 billion tce, representing an annual growth of about 1\%. After 2045, the total demand will be stabilized at around 30.0 billion tce.

(2) From 2014 to 2050, the non-fossil energy will increase by 3.8 times with an annual growth of $4.4 \%$, and its proportion to the supply of primary energy will ascend over 50\%; the supply of wind and solar 
energy will grow about 30 times and 80 times respectively, and their total proportion to the supply of primary energy will exceed $50 \%$.

(3) $\mathrm{CO}_{2}$ Emission will be reduced by $3 \%$ annually, displaying a large scissors difference with the consumption growth of primary energy (1\%). It will increase from 33.5 billion tons in 2014 to 36 billion tons in 2025, followed by negative increase. By 2050, the emission will drop to 11.5 billion tons, about $50 \%$ of that in 1990 .

\section{References}

[1] IEA, “World Energy Outlook 2016”, pp. 001-111, April 2016.

[2] BP, “International Energy Outlook 2016”, pp. 001-111, May 2016.

[3] SGERI, “Global Energy Review and Outlook”, pp. 89-180, May 2016. 